
\title{
28 Research Square \\ Triple-negative breast cancer in children: a case report
}

\section{Lexiang SHI}

Mudanjiang Medical University

Chengtao Chi

Mudanjiang Medical University

Yinan Zhang

Mudanjiang Medical University

Zhongwen Sun

Mudanjiang Medical University

Wenxian Yang

Kunming Medical College: Kunming Medical University

Yuchi Zhang

Mudanjiang Medical University

Jingcheng Wu

Mudanjiang Medical University

Jinping Li

Mudanjiang Medical University

Wanli Zhang ( $\square$ zhangwanli163@126.com )

Mudanjiang Medical University https://orcid.org/0000-0003-1847-3538

\section{Case Report}

Keywords: TNBC, BRCA, Secretory breast cancer

Posted Date: October 29th, 2021

DOl: https://doi.org/10.21203/rs.3.rs-1023528/v1

License: (c) (i) This work is licensed under a Creative Commons Attribution 4.0 International License.

Read Full License 


\section{Abstract \\ Background}

Triple-negative breast cancer (TNBC) is often considered a breast tumor with a poor prognosis that lacks or decreases the expression of estrogen receptor (ER), progesterone receptor (PR), and human epidermal growth factor receptor 2 (HER-2). It tends to occur in middle-aged and older women, and cases of TNBC in children are rarely reported.

\section{Methods}

We report a case of basal-like TNBC in a child at our hospital and review the related literature.

\section{Results}

Based on the patient's condition we performed a local mass excision, and despite the postoperative pathological diagnosis of TNBC, this case of basic TNBC had a good prognosis and was very different from conventional basic TNBC in many ways.

\section{Conclusions}

Although secretory breast cancer is a subtype of basal-like TNBC, it has its peculiarities and is completely different from basal-like TNBC. There is a need to raise awareness of the disease, select individualized treatment options, and prevent medical errors.

\section{Background}

Breast carcinoma is one of the common malignant tumors in humans. Its incidence has jumped to the top of the list of malignant tumors and is the main cause of death from malignant tumors in women ${ }^{[1]}$. Triple-negative breast cancer (TNBC)is a subtype of breast cancer that represents about $15-25 \%$ of breast cancer cases and is characterised by the absence or reduction of estrogen receptor (ER), progesterone receptor (PR), and human epidermal growth factor receptor 2 (HER-2) ${ }^{[2]}$. Compared to other breast cancer subtypes, TNBC is characterised by a higher recurrence rate, greater metastatic potential, and shorter overall survival time. TNBC is more common in middle-aged women compared with young people $\mathrm{e}^{[3,4]}$. TNBC in children is extremely rare and the pathogenesis is closely linked to genomic instability and mutations ${ }^{[5]}$. According to reports, the survival rate after metastatic TNBC surgery is very low ${ }^{[6]}$.

\section{Case Presentation}


An 8-year-old girl was presented to HongQi hospital with a right breast lump for 4 months. There was a hard mass under the right nipple, about $1.5 \mathrm{~cm}$ in diameter, with clear borders and good mobility. Her preoperative ultraphonic findings showed a hypoechoic lesion next to the right nipple, measuring approximately $1.4 \times 0.8 \mathrm{~cm}$ with clear borders, regular morphology, and a significant blood flow signal. She had no family history of the tumor. The tumor was resected after the completion of relevant examinations. The tumor was white to gray-red tissue with a volume of $1.6 \times 1.4 \times 0.7 \mathrm{~cm}$ and a solid graywhite cut surface. Histological findings showed that the main structure was papillary and also tubular with pink or pale pink cells, and secretory vacuoles and interstitial powdery secretions were seen (Figure 3). Immunohistochemical results showed ER few cells (+), PR (-), HER-2 (-), Ki-67 less than 10\% (+), CEA lesions (+), and P53 wild type. A diagnosis of TNBC (secretory breast carcinoma) was made. The child underwent a second resection. No tumor cells were found in the residual tumor cavity around the resection margin and biopsies of the anterior lymph nodes. Genetic testing showed an ETV6-NTRK3 gene fusion. After surgery, no herbal, radiotherapy, chemotherapy, or immunotherapy was administered. The child was followed up for 1-year and was in good health.

\section{Discussion}

In recent years, the incidence of TNBC has been increasing, becoming younger, and becoming a hot spot in clinical research ${ }^{[1]}$. Regardless of the fact that TNBC is generally considered to be highly malignant and has a very poor prognosis, a large number of documents display that TNBC is heterogeneous, showing

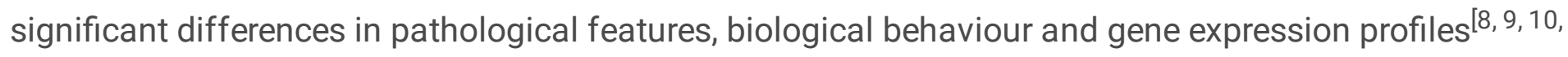
11, 12]. Therefore, understanding the TNBC classification has great clinical significance. At present, TNBC has a variety of typing methods and a variety of subtypes with different biological characteristics. By summarising the relevant literature on TNBC classification from 2009 to 2019 , Chen Lin ${ }^{[13]}$ found that the intraluminal androgen receptor (LAR), basal-like (BL), mesenchymal (MES) and immunomodulatory/basal-like immune activation (IM/BLIA) classifications were repeatedly mentioned in several TNBC classifications and are the more accepted ones currently. Joensuu $\mathrm{H}^{[14]}$ et al. divided TNBC into $B L$ and non-BL types, of which BL type accounts for $80 \%$ and has a high degree of malignancy and poor prognosis compared to non-BL type. BI-TNBC is divided into BL1 and BL2 types, which are characterized by overexpression of cell cycle-related genes and DNA damage response genes ${ }^{[15]}$ and have a strong proliferative capacity through these features. The top gene ontologies for the BL1 subtype are heavily enriched in cell-cycle and cell division components and pathways (cell-cycle, DNA replication reactome, G2 cell-cycle pathway, RNA polymerase, and G1 to S cell cycle). Elevated DNA damage response (ATR/BRCA) pathways accompany the proliferation pathways in the BL1 subtype. Increased proliferation and cell-cycle checkpoint loss are consistent with the elevated expression of the DNA damage response genes observed. The BL2 type displays a unique gene ontology involving growth factor signalling (EGF pathway, NGF pathway, MET pathway, Wnt/ß-catenin and IGF1R pathway), as well as glycolysis and gluconeogenesis. It has features suggestive of a basal/myoepithelial origin and exhibits higher levels of expression of TP63 and MME (CD10). 
Recent studies have shown that programmed death ligand 1 (PD-L1) and apurine/pyrimidine endonuclease 1 (APE1) play a role in the development of TNBC, and it is hypothesized that APE1 may be involved in regulating PD-L1 expression, promoting greater metastatic and invasive capacity of tumour cells and further participating in immune escape of tumours ${ }^{[16]}$.Accordingly, the emergence of immune checkpoint therapy may be a future research direction. If the process of homologous recombination (HR) is unavailable or impaired, this is referred to as 'homologous recombination deficiency' $(\mathrm{HRD})^{[17,18]}$. In this situation, DNA repair is more error-prone, which leads to genomic instability. Breast cancer susceptibility genes $1 / 2$ (BRCA1/2) are oncogenes that maintain genomic stability by playing a key role in DNA repair, cell-cycle arrest and transcriptional control. BRCA1 and BRCA2 play a role in the repair of DNA double-strand breaks (DSBs) through the HR process, with BRCA1 guiding the repair towards errorfree $\mathrm{HR}^{[19]}$. Loss of BRCA1/2 function leads to HRD ${ }^{[20]}$, and deletion or mutation of BRCA is closely associated with the development of TNBC. Ki67 significantly correlates with the proliferation level of tumour cells and is predictive of the prognosis of TNBC ${ }^{[21]}$. Compared to other subtypes of TNBC, BL-1 type has a high value-added rate ${ }^{[22]}$, indicating active tumour cell proliferation and a poor prognosis.

The diagnosis of breast cancer ${ }^{[23]}$ is made by clinical examination,radiological/imaging examination (including mammography, magnetic resonance imaging (MRI) ultrasonography, etc. and immunohistopathological examination. Early diagnosis of TNBC is difficult and relies on intraoperative rapid frozen section pathological examination and postoperative pathological findings. Surgery combined with neoadjuvant chemotherapy is the main treatment for TNBC ${ }^{[24]}$. The different histological subtypes of TNBC differ significantly in terms of clinical presentation, treatment and prognosis, and histological classification can help scientists develop the best individualised treatment approach. Platinum drugs and PARP inhibitors ${ }^{[25]}$ have a helpful effect on BL-1 type of TNBC. Platinum-based drugs affect the replication of double-stranded DNA in tumour cells by cross-linking with their DNA, leading to the death of tumour cells. They are very effective against TNBC caused by impaired repair of genetic damage due to BRCA gene mutations. Mutated BRCA cannot repair DSBs and will result in defects in homologous recombination and cause disease. PARP is a single-strand break (SSB) damage recognition and repair protein that plays an important role in starting SSB repair in DNA through base excision repair. PARP inhibitors can cause accumulation of SSBs, leading to the formation of DSBs for therapeutic purpose.

According to the worldwide classification of intrinsic subtypes, secretory breast carcinoma(SBC) is classified as basal-like TNBC ${ }^{[26]}$, but the clinical course of SBC is highly indolent. To date, there are no standard treatment guidelines for SBC. It in children is usually solitary, firm, well-defined, less than $20 \mathrm{~mm}$ in diameter, with good mobility, slow growth, and mostly without lymph node metastasis. In this case, the lesion was simply excised with no tumor cells at the margin, and no incisional enlargement or lymph node dissection was given. Our initial surgical decision was correct in terms of the results of the secondary surgical resection and lymph node dissection. Multiple surgeries caused physical, psychological and financial stress to the child and family to some extent. Our shortcomings were that our anticipatory judgment of the disease and preoperative examination were inadequately prepared, and 
rapid frozen sections were not performed intraoperatively. At the 1-year postoperative follow-up, the prognosis was good.

SBC belonging to BL-1 type of TNBC has a characteristic $t(12: 15)$ equilibrium shift, resulting in the ETV6NTRK3 gene fusion ${ }^{[27]}$. Its fusion gene product activates a certain pathway and eventually leads to the production of SBC. The clinical presentation of SBC is mostly benign, and surgical excision is the main option. Depending on the condition, local mass excision or breast-conserving surgical treatment combined with an anterior lymph node biopsy is desirable. However, when local excision is not extensive enough, SBC is at risk of recurrence and metastasis ${ }^{[28]}$. For SBC patients with infiltration and metastasis, a modified radical mastectomy or radical mastectomy combined with tyrosinase and Ras inhibitor

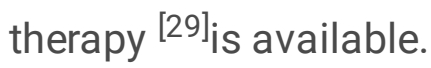

\section{Conclusions}

Although SBC is classified as BL-1 type of TNBC, it differs dramatically from BL-TNBC in terms of pathogenesis, clinical presentation, treatment and prognosis. Therefore, it is extremely important to choose the best individualized treatment plan. Some scholars ${ }^{[26,30]}$ believe that it is necessary to distinguish SBC from BL-TNBC in order to prevent misdiagnosis and mistreatment, and our view is consistent with theirs. Although these differences objectively exist, SBChas so far been classified as the BL-1 subtype of TNBC, whether this is due to the heterogeneity of TNBC and other factors remains to be further studied and proven.

\section{Abbreviations}

TNBC

Triple-negative breast cancer

ER

estrogen receptor

PR

progesterone receptor

HER-2

human epidermal growth factor receptor2

CEA

carcinoembryonic antigen

PD-L1

programmed death ligand 1

APE1

apurine/pyrimidine endonuclease 1

BRCA

Breast cancer susceptibility genes 
$\mathrm{BL}$

basal-like

DSBS

DNA double-strand breaks

SSB

single-strand break.

\section{Declarations}

\section{Availability of data and materials}

All data generated or analyzed during this study are included in this article and its supplementary information files.

\section{Competing interests}

Not applicable.

\section{Acknowledgements}

Not applicable.

\section{Authors' information}

First author: Shi Lexiang (1994-), male, master's degree student. Corresponding author: *Zhang Wanli, Male, Associate Professor, Deputy Chief Physician, M.S., M.S., Hongqi Hospital Affiliated to Mudanjiang Medical University, Department of Pediatric Surgery.

\section{Authors' contributions}

SLX, ZYN, SZW and ZYC: Pictures collection and all cowrite the manuscript. ZWL and SLX: reviewing and editing of the manuscript. All authors read and approved the final manuscript.

\section{Funding}

Not applicable.

\section{Consent for publication}

Consent for publication of images and information was obtained from the patient's parents.

\section{Ethical approval and consent to participate}

The Institutional Review Board of Hongqi Hospital, Mudanjiang Medical University, approved this study. 


\section{References}

1. Bray F, Ferlay J, Soerjomataram I, Siegel RL, Torre LA, Jemal A. et al. Global cancer statistics 2018: GLOBOCAN estimates of incidence and mortality worldwide for 36 cancers in 185 countries. CA Cancer J Clin. 2018;68(6):394-424. https://doi.org/10.3322/caac.21492.

2. Mills MN, Yang GQ, Oliver DE, Liveringhouse CL, Ahmed KA, Orman AG, et al. Histologic heterogeneity of triple negative breast cancer: A National Cancer Centre Database analysis. Eur J Cancer. 2018;98:48-58. https://doi.org/10.1016/j.ejca.2018.04.011.

3. Kumar P, Aggarwal R. An overview of triple-negative breast cancer. Arch Gynecol Obstet. 2016;293(2):247-69. https://doi.org/10.1007/s00404-015-3859-y.

4. Agarwal G, Nanda G, Lal P, Mishra A, Agarwal A, Agrawal V, et al. Outcomes of Triple-Negative Breast Cancers (TNBC) Compared with Non-TNBC: Does the Survival Vary for All Stages? World J Surg. 2016;40(6):1362-72. https://doi.org/10.1007/s00268-016-3422-4.

5. Safonov A, Jiang T, Bianchini G, Győrffy B, Karn T, Hatzis C, et al. Immune Gene Expression Is Associated with Genomic Aberrations in Breast Cancer. Cancer Res. 2017;77(12):33173324.https://doi.org/10.1158/0008-5472.CAN-16-3478.

6. Nomi T, Sho M, Akahori T, Hamada K, Kubo A, Kanehiro H, et al. Clinical significance and therapeutic potential of the programmed death-1 ligand/programmed death-1 pathway in human pancreatic cancer. Clin Cancer Res. 2007;13(7):2151-7. https://doi.org/10.1158/1078-0432.CCR-06-2746.

7. Bacinschi XE, Zgura A, Safta I, Anghel R. Biomolecular Factors Represented by Bcl-2, p53, and TumorInfiltrating Lymphocytes Predict Response for Adjuvant Anthracycline Chemotherapy in Patients with Early Triple-Negative Breast Cancer.Cancer Manag Res. 2020;12:11965-11971. https://doi.org/10.2147/CMAR.S274104.

8. Portha H, Jankowski C, Cortet M, Desmoulins I, Martin E, Lorgis V, et al. Tumeurs localisées du sein triple négatives en 2016: définitions et prise en charge [Non-metastatic triple-negative breast cancer in 2016: Definitions and management]. Gynecol Obstet Fertil. 2016;44(9):492-504. French. https://doi.org/10.1016/j.gyobfe.2016.06.014.

9. Lyons TG. Targeted Therapies for Triple-Negative Breast Cancer. Curr Treat Options Oncol.2019;20(11):82. https://doi.org/10.1007/s11864-019-0682-x.

10. Geyer FC, Pareja F, Weigelt B, Rakha E, Ellis IO, Schnitt SJ, et al. The spectrum of triple-negative breast disease: high and low grade lesions. Am. J.Pathol. 2017;187(10):2139-2151. https://doi.org/10.1016/j.ajpath.2017.03.016.

11. Mills MN, Yang GQ, Oliver DE, Liveringhouse CL, Ahmed KA, Orman AG, et al. Histologic heterogeneity of triple negative breast cancer: A National Cancer Centre Database analysis. Eur J Cancer. 2018;98:48-58. https://doi.org/10.1016/j.ejca.2018.04.011.

12. ChenLin, LuoBin. Progress in subtyping triple negative breast cancer. Chin.J.Cancer Prev. Treat. 2020,27(20):1683-1690. https://doi.org/10.16073/j.cnki.cjcpt.2020.20.12. 
13. Joensuu H, Kellokumpu-Lehtinen PL, Huovinen R, Jukkola-Vuorinen A, Tanner M, Kokko R, et al. Adjuvant capecitabine, docetaxel, cyclophosphamide, and epirubicin for early breast cancer: final analysis of the randomized FinXX trial. J Clin Oncol. 2012;30(1):11-8. https://doi.org/10.1200/JC0.2011.35.4639.

14. Lehmann BD, Bauer JA, Chen X, Sanders ME, Chakravarthy AB, Shyr Y, et al. Identification of human triple-negative breast cancer subtypes and preclinical models for selection of targeted therapies. $J$ Clin Invest. 2011;121(7):2750-67. https://doi.org/10.1172/JCl45014.

15. LuoHao, DaiNan, YangBo, DaixiaoYan, YangyuXin, LimengXia, et al. Expression of PD-L1 and APE1 in triple-negative breast cancer tissues and its clinical significance. J. Mod. Oncol. 2021;29(21):37473751. https://doi.org/CNKI:SUN:SXZL.0.2021-21-010.

16. Lips EH, Mulder L, Hannemann J, Laddach N, Vrancken Peeters MT, van de Vijver MJ, et al. Indicators of homologous recombination deficiency in breast cancer and association with response to neoadjuvant chemotherapy. Ann Oncol. 2011;22(4):870-6. https://doi.org/10.1093/annonc/mdq468.

17. Helleday T. Homologous recombination in cancer development, treatment and development of drug resistance. Carcinogenesis. 2010;31(6):955-60. https://doi.org/10.1093/carcin/bgq064.

18. Evers B, Helleday T, Jonkers J. Targeting homologous recombination repair defects in cancer. Trends Pharmacol Sci. 2010;31(8):372-80. https://doi.org/10.1016/j.tips.2010.06.001.

19. Scully R, Xie A, Nagaraju G. Molecular functions of BRCA1 in the DNA damage response. Cancer Biol Ther. 2004;3(6):521-7. https://doi.org/10.4161/cbt.3.6.842.

20. Pérez-García J, Soberino J, Racca F, Gion M, Stradella A, Cortés J. Atezolizumab in the treatment of metastatic triple-negative breast cancer. Expert Opin Biol Ther. 2020;20(9):981-989. https://doi.org/10.1080/14712598.2020.1769063.

21. Jovanović B, Mayer IA, Mayer EL, Abramson VG, Bardia A, Sanders ME, et al.A Randomized Phase II Neoadjuvant Study of Cisplatin, Paclitaxel With or Without Everolimus in Patients with Stage II/III Triple-Negative Breast Cancer (TNBC): Responses and Long-term Outcome Correlated with Increased Frequency of DNA Damage Response Gene Mutations, TNBC Subtype, AR Status, and Ki67. Clin Cancer Res. 2017;23(15):4035-4045. https://doi.org/10.1158/1078-0432.CCR-16-3055.

22. Aebi S, Davidson T, Gruber G, Cardoso F; ESMO Guidelines Working Group. Primary breast cancer: ESMO Clinical Practice Guidelines for diagnosis, treatment and follow-up. Ann Oncol. 2011;22 Suppl 6:vi12-24. https://doi.org/10.1093/annonc/mdr371.

23. Rouzier R, Perou CM, Symmans WF, Ibrahim N, Cristofanilli M, Anderson K, et al. Breast cancer molecular subtypes respond differently to preoperative chemotherapy. Clin Cancer Res. 200511(16):5678-85. https://doi.org/10.1158/1078-0432.CCR-04-2421.

24. Lee YM, Oh MH, Go JH, Han K, Choi SY. Molecular subtypes of triple-negative breast cancer: understanding of subtype categories and clinical implication. Genes Genomics. 2020;42(12):13811387. https://doi.org/10.1007/s13258-020-01014-7. 
25. Jin MS, Lee H, Woo J, Choi S, Do MS, Kim K, et al. Integrated Multi-Omic Analyses Support Distinguishing Secretory Carcinoma of the Breast from Basal-Like Triple-Negative Breast Cancer. Proteomics Clin Appl. 2018;12(5):e1700125. https://doi.org/10.1002/prca.201700125.

26. Ghilli M, Mariniello MD, Scatena C, Dosa L, Traficante G, Tamburini A, et al. Male secretory breast cancer: case in a 6-year-old boy with a peculiar gene duplication and review of the literature. Breast Cancer Res Treat. 2018;170(3):445-454. https://doi.org/10.1007/s10549-018-4772-4.

27. Sharma V, Anuragi G, Singh S, Patel P, Jindal A, Sharma RG. Secretory Carcinoma of the Breast: Report of Two Cases and Review of the Literature. Case Rep Oncol Med. 2015;2015:581892. https://doi.org/10.1155/2015/581892.

28. Cadoo KA, McArdle O, O'Shea AM, Power CP, Hennessy BT. Management of unusual histological types of breast cancer. Oncologist. 2012;17(9):1135-45.

https://doi.org/10.1634/theoncologist.2012-0134.

29. Laé M, Fréneaux P, Sastre-Garau X, Chouchane O, Sigal-Zafrani B, Vincent-Salomon A. Secretory breast carcinomas with ETV6-NTRK3 fusion gene belong to the basal-like carcinoma spectrum. Mod Pathol. 2009;22(2):291-8. https://doi.org/10.1038/modpathol.2008.184.

\section{Figures}
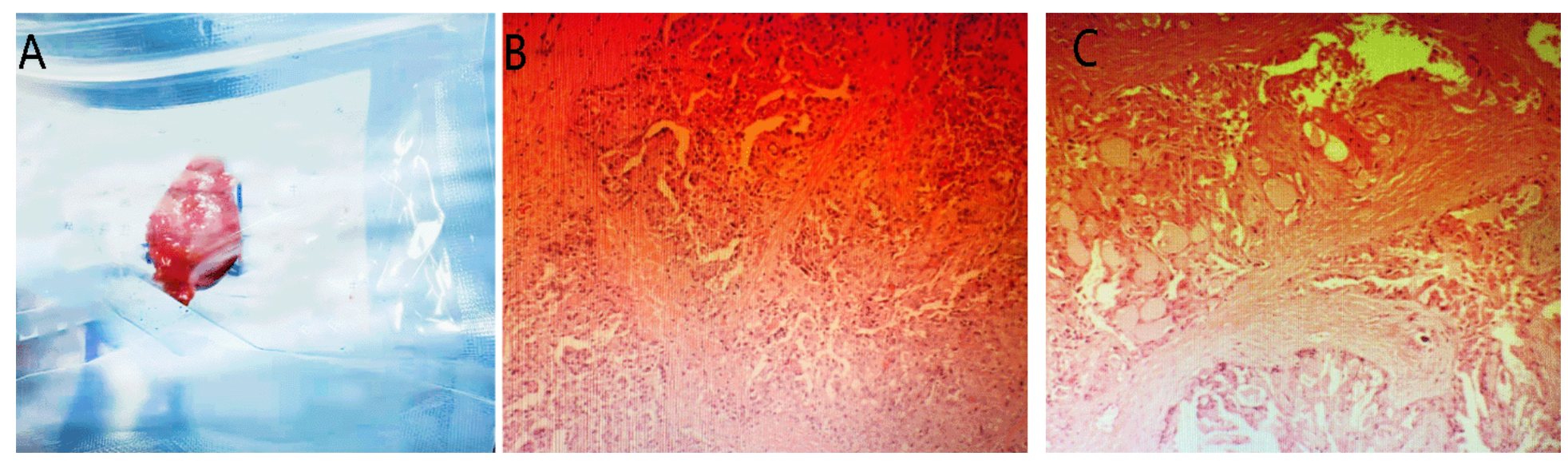

Figure 1

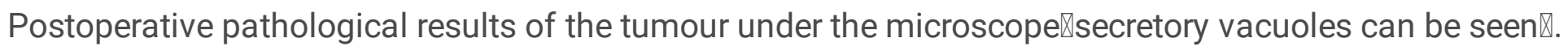

\section{Supplementary Files}

This is a list of supplementary files associated with this preprint. Click to download.

- check.jpg 